\title{
Women Watching Television: Surfing Between Fantasy and Reality
}

\author{
Aanmona Priyadarshani and Samia Afroz Rahim
}

\begin{abstract}
Young women are increasingly experiencing greater visibility and mobility in Bangladeshi society. The new public spaces they occupy together with the more traditional private spaces are greatly mediated by the narratives beamed on television. This article looks at how Bangladeshi women engage with television and the meanings and choices they derive from it. It examines which elements the women choose to adopt and which they discard as being alien to their lifestyles. Through these choices, they can be active subjects in the media narrative, selecting and adapting pieces to fit their purpose rather than being a passive consumer of television outputs. Television has blurred the boundaries between the public and private and its power to influence representations is significant. If this power can be used to break down traditional stereotypes and replace dominant stories and images, it could be an important step towards new ways of being and perhaps a pathway of women's empowerment.
\end{abstract}

\section{Introduction}

Nowadays, young Bangladeshi women's lives are greatly influenced by urban culture and popular media. They occupy and are visible in public spaces in ways not previously seen. Far more women are attending university or becoming wage-earners than before. The private spaces that these women inhabit have also been transformed. Homes that were considered secluded are now made more public through technology and media. The television particularly has captured imaginations across economic, sociocultural and political boundaries in Bangladesh. Television is a powerful means of conveying ideas and norms and is a pivotal tool for shaping identity. While reflecting values, television as part of media also reconstitutes them; their interplay fashions women's subjectivities.

This article will outline how women in urban and peri-urban areas in Bangladesh engage with television and attach meaning to images and representations that may or may not have been the producer's intention. The pleasure involved in watching television will be explored and we will attempt to highlight the notions of femininity, sexuality and self that are experienced. We ask what are the dominant narratives, how are they interpreted and do the interpretations shape viewers' values and sense of self? Does the influence of images end with the 'off switch' or does it last beyond this into daily lives? And does television viewing open up new spaces for women (emotionally and psychologically): are these moments of escape and recognition crucial to experiencing new realities or do they simply reinforce the limitations within which women live?

Our analysis draws on research on television viewing with women aged 15-45, from different economic and social backgrounds, occupations, marital status and locations. Most belonged to the lower-middle and economically lower class, and were either housewives, students or working as day-labourers, garment workers, or domestic help. At the confluence of much change, particularly migration from rural areas, negotiation with the new spaces and relationships that they encounter, and instability and mobility in their employment, they represent the majority of women in Bangladesh. We also interacted with middle-class university students, a group undergoing immense transition, as they engage in a process of learning and often having to travel miles from their homes to pursue their studies. 
Through focus-group discussions, we were able to get a broad picture of what the viewers watched and why as well as the different kinds of relationships they had with television viewing. To understand the experience of television viewing, we undertook household interviews. We also conducted participant observation, watching television with the viewers to note who possessed the remote control, with whom women watch television, whether this watching changes according to who is present, what interruptions there are, and which activities take place simultaneously. We also analysed popular television programmes and films to understand the leading narratives around gender, sexuality, romance and social relations.

\section{Dominant narratives}

Our research found that women predominantly view Indian and Bangladeshi channels. The linguistically varied, nationally separate and religiously different narratives offer a very interesting space for identity formation. The depiction of class dominates Bangladeshi, Indian Bangla and Hindi serials, with Hindi programmes in particular focusing on the upper classes in shows like, Kasamh Se. In contrast, the Bangladeshi serials predominantly portray the middle class, but with an upper-middle-class veneer; for example Dainik Tolpar shows a middle-class family living in a modern apartment in an exclusive area, something in reality this class could not afford. However, in Bangla films, both Indian and Bangladeshi in origin, class identity often shifts through the course of the film and depictions of characters moving up the social ladder are common.

Family is an important issue. Hindi programmes tend to depict large, extended families and focus on the private sphere. Bangladeshi ones often show small nuclear family life, with less demarcation between public and private worlds. This urban, nuclear middle-class family is a new and increasingly common image, replacing the rural-urban joint-family that would have been depicted a decade ago. Bangla films, on the other hand, represent a broader spectrum of family structures including single-parent, adopted and foster families. Within the family, heterosexual marriage is the basic relational structure. However, representations of sexuality previously embodied by married couples through symbolism are becoming more diverse and explicit, particularly in Hindi serials and Bangladesh movies. These include extra-marital affairs both by men and women - and polygamous marriages.

It is usually through the narratives of romance, jealousy and revenge that portraits of the main characters in serials and films are framed. Whether male or female characters are portrayed as socially acceptable or not depends on their enactment of family duty. Binaries maintained between gender roles are further distinguished by posing an opposition between the good and bad character. The good woman is depicted as a devoted wife and mother with limited ambition. In contrast, the bad woman is aggressive in the pursuit of her interests and dominating over her family. Her wickedness often manifests itself physically in arched eyebrows, long painted fingernails and a cold, hard stare.

A good man must earn enough to adequately sustain his family. He is usually the head of the family, making all the important decisions and is portrayed as sensible and dependable. However, extra-marital affairs, considered taboo for women, are more acceptable for the leading male character. Reasons for validating his actions include his wife being uncaring or irresponsible or unable to bear children. The bad man is shown as gaining his wealth through ill means or is unemployed and scheming. Any loss of income, even if it is unexpected, is seen as failure on the part of the man.

These narratives that make distinctions in class, depict family relations, delineate gender roles and the characteristics of good and bad individuals represent dominant accounts of broader social values. This is the process of 'encoding', through which values are embedded in the texts and images to represent and recreate social contexts.

\section{Power dynamics and negotiations while viewing}

The entire experience of viewing is strongly moderated by power relations and negotiations between viewers. In most households, we found nuclear families negotiating their viewing preference around a single television. Women were always extremely busy with household duties but managed to carve some time for viewing during the afternoons; working women 
in the weekend afternoons, and those who are housebound, daily. During this time, female neighbours visit one another and women mostly watch television together. At other times, television viewing has to be negotiated with family members, whose preferences often override theirs. When male members of the household are present, they assume control over what is shown on television.

Negotiation over viewing also takes place in different kinds of familial relationships. Decorum is maintained between mothers and sons and sons-in-law, and sisters in the presence of their brothers. In the lower-middle-class neighbourhood of Agargaon, a family was watching the Hindi film Main Prem Ke Diwani Hu together, when Bollywood actress Kareena Kapoor appeared wearing a swimming costume, something that seemed inappropriate for the mother to watch in front of her sons. The mother left the room and beckoned her daughter to follow. The sons had no qualms watching these scenes in front of their mother and sister and did not move their eyes from the screen. Regardless of age difference, this decorum is always maintained by women - the male members, however young, do not have to censor their viewing in front of anyone. Age is relevant however when viewers, especially women, are watching television in the presence of 'murubbis' (older, respected persons), and in university halls, where juniors acquiesce to the viewing preferences of senior students. In Dhaka University, we saw senior students controlling the remote, despite around 40 members of other academic years being present. Marital status also creates distinctions between viewers by giving those who are married the license to view more than those who are not. In the slum area of Korail, one married woman said, 'Romance and bed scenes should not be seen too much by young, unmarried women, otherwise, they will become bad. We can see all of this because we have husbands'.

Other factors impinge on women's viewing patterns. Attempts to create time in hectic routines to indulge in television are thwarted by electricity cuts, forcing women to rearrange their next day schedules to catch reruns. Another issue is religious events - during Ramadan, women read the Koran, break their fasts and say the supplementary Tarabee prayers when they might otherwise watch television. All these practical and socioreligious realities influence their viewing patterns and entail negotiation for women viewers.

\section{Viewers' interpretations}

Despite these negotiations and codes of conduct, television opens up different worlds both familiar and unfamiliar. Intersections of class, gender, social position, language, age, religion and other indices of identity, all play a role in determining how women interpret the narratives they watch onscreen and associate meaning to them.

Theories of popular culture divide between those who see media as omnipotent and people as merely passive consumers (Adorno 1991), and those who maintain people can have an active and creative engagement (Fiske 1989). In our research, we have seen that there is significant engagement and negotiation between media producers and consumers to create meaning. The manufacturing of this meaning is a complex process, involving the producers representing certain dominant images for imagined audiences, and consumers interpreting these texts via multiple identities, whose allegiances vary according to time and space (Hall 1997). Meaning is not created uniformly or distinctly, it is forged by producers and consumers of media, in an uneven process that constantly feed off one another. Viewers are in a state of constant negotiation as they watch television - continually judging what they view, assimilating the new values they encounter and using them to reshape their own, and rejecting narratives that are alien to them. The tropes of propriety and impropriety that allow viewers to relate to what is on television are also influenced and affected by how they interpret these.

One of these tropes that frame viewers' reception of images is their idea of masculinity and femininity. Social values and representations of masculinity onscreen favour athletic, goodlooking men, educated and earning sufficiently for their family, 'A hero should have a muscled, tall body like Salman Khan or Hrithik Roshan!' chorused many female respondents, spanning both middle-class and lower-income groups. But in some cases, muscled bodies are celebrated in certain women. 'We love watching female wrestling! That women have so much physical strength, we couldn't imagine it. It gives us great "foorti" to watch them!' said a married woman in 
the semi-urban area of Koitta, Manikgonj. Many women however, still adhere to conventional models of femininity, perceiving female wrestling as despicable, for example a woman from Gerua commented, 'Such activities do not suit women at all! It is bad!' While some traditional models of gender are still being upheld, simultaneously some respondents want to see a transformation of these in the media. Jahangirnagar University students said that they want to see new images of women onscreen, such as career-oriented women engaging in professions dominated by men like business. Some students said:

\section{We should break the stereotypes that are portrayed in the media: married women are always shown busy with making a home and tending to children, the good wife is one shown as someone looking after her in-laws and tolerating all manner of injustice, dark women are constantly shown trying to become fair and pretty, all this should change and new images and stories of women need to be depicted.}

They added:

We see on television a nuclear family where the man is the breadwinner, or sometimes the husband and wife together maintaining the family, but we want to see serials where it is the wife who is the sole breadwinner. In scenes that show men driving around in their cars and motorbikes, they have their wives next to them; we'd now like to see women in the driver's seat.

They also said that instead of the traditional man proposing marriage to a woman, romance should show the woman proposing to a man. Some students said that traditional mother-inlaw/daughter-in-law tensions are shown too often and that harmonious relationships between inlaws should be portrayed. These comments reveal that women want to see a change in women's representation onscreen, while they may or may not simultaneously subscribe to certain gender norms and relations.

Another criteria that viewers take cues from to define proper femininity is clothing. Clothing is a means to relate to the characters onscreen our viewers preferred to see actresses who play a married role in sarees, perhaps reflecting their own values about the appearance of a married woman. But it does not necessarily reflect how the viewers dress in reality. Viewers enjoy seeing unmarried female roles exhibiting a wider array of clothing, ranging from the sari to shalwaar kameez, lehengas and western wear. Satellite television has made the lehenga and western wear familiar to viewers who did not have a culture of wearing them even two decades ago. Bodily form also changes the parameters of modesty; our respondents spoke derisively of overweight women wearing fitted clothing or clothing that does not cover their 'fat' bodies and deemed them vulgar. But when they see slender women onscreen dressing similarly, they appreciate their style. Notions around modesty regarding clothing are also mirrored in ideas around romance.

The construction and meaning of romance varies according to changing times and contexts. Some older participants commented that they preferred the depictions of romance screened during their youth - a boy and girl riding a rickshaw together and wooing with sweet conversation, the most intimate physical contact was a touching of hands. Our younger respondents, particularly female factory and household workers, said 'Romance should involve glancing at each other coyly, holding hands, going out to eat at restaurants, hugging, and kissing - these are so natural!' But some of these younger respondents added that 'Everything should have a limit [matra]'. They considered scenes depicting sexual foreplay and intercourse not permissible and that some modesty must be maintained.

The notion of modesty varies though among women of different ages and educational background. While younger women in the lowerincome group preferred a censoring of explicitly sexual scenes, university women claimed they would like to see all physical expressions of love and romance on the television. One Jahangirnagar University student commented:

Whenever we hear the word 'sex' we sit up straight. We think it is something that only happens in the bedroom between a husband and wife. Sexual scenes give us pleasure. I am not saying that we will like all sexual scenes. But scenes that are heterosexual or show husband-wife relations excite us. Whoever denies this is a hypocrite. Just because we are not married doesn't mean that we have no sexual feelings.

Another added, 'Sex is a part of life. Among those of us who are at university and having affairs, many are having physical relationships. 
This is no longer the era where women remain virgins until marriage'. Some students considered sex to be an area of learning as well:

I think that sex is an art, you can't enjoy sex if you lie like a dead person; you have to play an active role. And if anyone wants to learn and have sex in different ways and positions, then society should not stop this in the name of values and morals.

The comments by the Jahangirnagar University students indicate a shift in attitudes towards sex and sexuality among the middle-class younger generation. Where dominant narratives portray women passively in matters of sex, these young women advocate an active role and an exploration of pleasure. Traditional values frown upon pre-marital sexual relations, but these seem to be an ordinary part of their lives. While university students are defying certain norms and values, some identities and relationships remain important to them. The male-female union was seen as an ideal by all the Jahangirnagar University respondents, as it was by all our other respondents.

That the Jahangirnagar University students were so open to watching sexually explicit material may be due to their distance from their families outside of Dhaka. The Dhaka University students on the other hand did not think it was appropriate to view intimate scenes. One student commented about a serial, 'The actress was lying on the bed and her husband caressing her belly; this relationship between a husband and a wife needn't be shown on television; children may see this and how bad is that'. Dhaka University respondents in general seemed more conservative in their preferences than their Jahangirnagar counterparts and this may relate to them living in the capital, often with family around, compelling them to be cautious about the values they hold. However, although these students made strong statements about appropriate viewing, our experience from participatory observation showed they watch anything and everything that is screened. Steamy music videos showing provocative male and female dancers were the mainstay of their viewing, but they also watched Hindi and English movies, and never switched channels when intimate scenes were displayed. Our research has revealed time and again that what people say when asked about viewing habits is often very different from what they actually do, perhaps because in detailing what they watch they are also self-censoring to provide answers that seem more 'proper'.

Notions of propriety and impropriety are strongly influenced by what individuals experience as their reality. People's immediate living situations influence what they are drawn to on television, both in terms of what they like seeing reflected of their direct physical reality as well as their fantasy. A Jahangirnagar University student commented:

\section{Ifind my surroundings reflected on television.}

Whatever is surrounding me on four sides, that has made up my existence; that is what has made me.

Therefore when I see all this reflected on television, I feel as if I am looking at myself.

Students liked watching serials reflecting university life - romances between students, hours whiled away with friends - all of this finds resonance in their lives.

A few programmes found a following among viewers all across the classes. One is the news. A woman in Korail slum area commented:

We can find out all that is happening in Bangladesh
through the news. For instance, there is flooding in the
South, near the Bay of Bengal. It is not possible for
us to go there personally and see. We don't even have
the money to go if we wanted to. If the television is
there, we can get news daily, as and when it happens.

As our research was being conducted just prior to elections, the news was watched frequently and the topics debated with much passion. The political context during this time was unsteady, with politicians being charged with corruption, the rising prices of goods and preparations for the elections, all making the media important to our respondents. The political environment affects people's lives in direct ways, as can be seen by a woman from a Hindu household in Koitta, who said:

Of course we watch the news! There is tension because we are wondering when the elections will be held. We are tense because our community is very vulnerable. If the government changes, if Hasina comes, our situation might be better. See today, Khaleda got released from jail; now her cronies here will flex their muscles. My husband's business will suffer then. 
But politics does not just affect minority communities, every Bangladesh citizen is affected by the political and economic situation. The women we talked to said that they watch the news to learn about food price fluctuations and keep abreast of economic conditions facing the country. Thus, the very real circumstances affecting people's lives also draw them to television, besides the pleasure and fantasy it offers.

The depiction of reality is important for forming connections with viewers. But sometimes in representing the realities of the majority, television can make the lives of minorities more invisible, compelling them to seek mediums that express their lifestyles even if this belongs to a different region, country or language. During our field research in Koitta, Manikgonj, we found Hindu households there watching not Bangladeshi Bangla channels but West Bengali Bangla channels and Indian Hindi channels such as Akash Bangla and Star Utsav; channels that some of us researchers had never seen before. ${ }^{2}$ We were researching in Koitta the week preceding the Hindu festival of Durga Puja and our participants were engrossed in watching the Puja programmes these channels were airing. Sitting in those households felt as if we were inhabiting another world; the images and narratives onscreen - of Hindu mythological symbols and rituals - were distinct from anything else we had witnessed our other respondents watching over the past three months of field research. One woman commented that they enjoy watching Akash Bangla and Star Utsav because,

... it showes women dressed well, wearing a sindoor, maintaining a nice family... These channels show the Puja and the temple; when someone is in trouble, they show the person falling on Ma's (the Goddess's) feet and praying to her, just the way we do; you can see brass utensils being used - do you ever see them depicted in the channels here? Never!

It is because the Bangladeshi channels seldom portray their daily lives and religion that this member of the Hindu household in Koitta is watching Indian channels rather than what the majority of viewers in Bangladesh are watching. Television has made it possible to find elements of one's identity in narratives spanning different nation-states, cultures, ethnicities, class and gender. Technology, and in particular the media through narratives, enables one to transcend geopolitical boundaries in affirming identities and gaining a sense of belonging.

While some women watched television because it reflected certain aspects of their lives, others were watching television precisely because it offers such different realities. Women living in the slum areas of Korail and Bhasantek told of how they enjoyed watching serials showing the lives of those who live much differently from them. 'By watching all this, we can learn what happens in other women's lives; so what if none of this happens in our own lives, we can hope for it for our children', said a young mother in Korail. A woman in Bhasantek, when watching a West Bengali film showing a couple going to a dance party, commented: 'Eesh! Look at rich people dancing! It's most absurd!' To her, going to dance parties was something so alien that it only mustered incomprehension and rejection. It resembled nothing she would ever do in her life, but she enjoyed the film by distancing herself and imagining it occurring in other people's lives. It is by relating to one's own reality and imagining of the realities of others that viewers become so engrossed in television. This envisaging of other ways of existence, both for oneself as well as for others provide viewers with a rich landscape for fantasies.

Analyses of the relationships women share with fantasies have been complicated historically. The pleasures that women get through indulging in fantasies, either through reading romance novels or through watching films, have often been dismissed as a source of false consciousness and pandering to patriarchal norms. Authors such as Janice Radway (1991) and Ien Ang (1982) have challenged this, stating that fantasies do not simply recreate the status quo, they offer space to reimagine social relationships in ways that may even challenge them, and need to be given importance in order to fully understand women's realities.

The space for fantasising that television offers is only limited by one's imagination. During our research, we watched television in one-room homes, with walls of corrugated steel containing so many holes that old newspapers were pasted on to provide some privacy, among viewers who watched the opulent lives onscreen mesmerised. 'We love watching the lives of the rich', said one young woman in the slum area of Korail. The 
glamorous ambience and world of luxury seem to represent their fantasies and express their fascination towards realities that are out of their reach. The poverty and distress in their lives seem to evaporate as they are transported from their world to experience plenitude and privilege, however vicariously and fleetingly.

The television offers space to feed emotions and desires that satiate a viewer's fantasies so that fissures in representation are filled in seamlessly by the power of imagination. One of the most common themes that our viewers enjoy watching is the battle between a mother-in-law and daughter-in-law. Our respondents enjoyed this narrative because it gave them pleasure to see a nasty daughter-in-law taught a lesson or a conniving mother-in-law meted her punishment. A respondent from Gerua commented:

A daughter-in-law is abused by her mother-in-law; after that the mother-in-law is taught a lesson. She (the mother-in-law) then starts to feel sorry and thinks 'Why did I do this.? I shall never do it again'. When she understands, it makes us feel very good.

A married woman in Bhasantek said, 'We don't just like rebellion. At first she must try to be tolerant. If the situation pushes her against the wall, only then should she revolt'. This woman enjoyed narratives not just showing revolt, but also showing the dilemma of putting up with abuse and the tensions that this builds until the moment when tolerance wears out and the protagonist stands up for herself and reclaims her ground. Watching these conflicts onscreen may perhaps offer hope for women who have to endure such injustices themselves. An unmarried respondent in Bhasantek said:

Seeing women protest is a matter of learning. It shows that women can stand up against injustice. These should be shown much more on television. Then we can learn that women will not tolerate injustice silently. And those who oppress will learn that women will not stand for it.

That the unmarried woman spoke so plainly against any oppression by in-laws and the married respondent but was much more careful about rebelling, highlights the tenuous position of the married woman, who has to balance her role as a good daughter-in-law with any injustices she suffers.
Television is a terrain that harbours dissent and unfulfilled desires, so that desires that cannot be had off-screen can be experienced vicariously. Respondents from all ages, classes and locations said they loved watching romance, particularly courtship and love between a husband and wife. The story of Salma, ${ }^{3}$ a young married woman in Gerua, highlights the influence of onscreen romance in her life. She and her two-year-old son live mostly in her parents' home, as her husband is away with the army. Salma told us how she and her husband met and got engaged - he came to see her at her parent's home and fell in love at first sight. They got engaged quickly and at the ceremony, her fiancé sang a romantic song. During their engagement they wrote frequently, and she saved every letter from him, and reads them often. He once gave her a red rose, which she kept. Many years into their marriage, following their son's birth, she showed him the rose, and he was taken by surprise, 'You have saved so many things from me? You truly do love me! I think I fail to appreciate you sometimes. But you truly love me!' Salma said, 'See, wasn't it good to have saved that memento from him? I now have my husband's love'.

The influence of romance as depicted on television is palpable in Salma's life and it seems to have charted expressions of love for her. When their romance was just budding, she had sent a letter, sprayed with perfume, saying 'You are only mine!' to her husband-to-be, she says he still carries that note from her in his wallet. She told of the hours they talk on the phone when her husband is away, often singing songs from Hindi and Bangla films to each other and these infuse their long-distance relationship with passion. Salma's exuberant recounting of the romance they share was punctuated by sighs about the girlfriends he had, about his tendency to place confidence in his mother more than her, and the fact that he never brought her any gifts when he came to see her. On one of our visits, she sat red eyed and glum saying how carefree her life had been when she was unmarried and how fortunate we researchers were to be single. That her life was such juxtaposition between the romance she said she shared with her husband and the reality of it - her husband's absence for ten months of the year, her suspicions of him being with other women - was striking. It seemed as if fantasising about romance sustained her while she dealt with her missing husband and the tensions that 
her conjugal life brought. Salma loved watching romance onscreen as it seemed to offer her experiences that may have been missing in her life. To us researchers, it seemed as if watching television was offering Salma a substitute to life itself, allowing her to experience pleasures that she may not be able to experience otherwise.

Television provides an escape from sorrow, where viewers can harbour dissenting desires, imagine alternative existences and vicariously experience other lives. The envisioning of new realities facilitates an engagement with the narratives onscreen that occur not only while viewing, but even when the television is switched off. During our research, we found women incorporating dialogues heard onscreen into their own conversations. In Bhasantek, one household had young women gathering every afternoon to watch television together while doing piece work embroidery. While chatting, they would pick up on dialogue from the Hindi movies. When one of the girls asked another to pass along a spool of thread, she replied, 'Nahe, nahe, kabhe nahe (no, no, never)!', mimicking a Hindi film. ${ }^{4}$

We found narratives on television incorporated not only in everyday speech of our respondents, but also in what they wore. In each of our field sites, respondents said they tailored clothing according to the fashions portrayed onscreen. Our middle-class respondents purchased these designs from local fashion houses, but buying outfits from shops is beyond the means of the lower-middle and lower income groups, so they made copies of the designs themselves often purchasing a cheaper variety of material. In assimilating the screen designs, viewers have to negotiate with their own realities and customs. For instance, a participant in Bhasantek wore a tank top underneath a shalwaar kameez that she requested to have tailored with a big neck so that the tank top straps could be seen. She had seen the Indian actress Katrina Kaif wearing this and wanted to emulate her style. The young woman explained that during the day, she wraps herself with a big dupatta so that her straps are concealed, and she can walk about with modesty; when she is at home or with friends, she removes the dupatta. Through such assimilation of the styles and aesthetics onscreen, young women are able to strategically exercise their choice and straddle between what is presented on television and that which is acceptable to their own society.

\section{New spaces}

Women experience different worlds, escape from their own realities and harbour dreams through the space that television opens up. This enables the woman to become a subject - choosing, judging, and discarding the narratives seen onscreen - rather than an object, viewing without participation. The television has blurred the boundaries between the public and the private. Spaces that were for long kept separate now lie close together, often overlapping, erased of their distinctions. Stories of the private are made public to mass audiences, while viewers encounter the public sphere through television in the confines of their home. The boundaries of viewers' knowledge are expanded through the information, narratives and representations onscreen. Besides presenting universes previously unknown, the television also offers opportunities for a temporary escape from the realities of life. It lays open a world of fantasies in which women can vicariously experience all that they desire, kindling hopes and allowing the imagining of new realities. The pleasures of viewing television do not only remain in the realm of fantasy, they are translated into reality through the myriad ways that women incorporate the narratives onscreen into their daily lives.

Our research has found that it is possible for women to imbibe different subjectivities through their watching of television. Even although the viewers may find comfort in narratives that reinforce existing power structures because it is so familiar to their realities, the spaces that television offer for escape, fantasy and participation all lead to a reconfiguring of their lives through women's conscious and active selection and enactment. The potentialities of empowerment remain nascent now but can be realised through further engagement. For a start, we can begin by breaking stereotypes, replacing dominant narratives with a diversity of representations, and having media producers cater to the pleasures of women's viewing. Time and further research might show whether engagement with television will lead to new ways of being or simply reconfigure the existing parameters of their lives. 


\section{Notes}

1 For instance, Amma Jaan, Hira, Shanto Keno Mastaan.

2 Akash Bangla is not offered by many cable operators in parts of Dhaka, perhaps because the cable operators do not anticipate much

\section{References}

Adorno, T.W. (1991) The Culture Industry: Selected Essays on Mass Culture, London: Routledge

Ang, I. (1982) Watching Dallas: Soap Opera and the Melodramatic Imagination, London: Routledge

Fiske, J. (1989) Understanding the Popular, London: Unwin Hyman demand for it and therefore leave it out of their selection.

3 Not her real name.

4 From the Hindi film Sangam, starring Boijonji Mala and Raj Kapoor.

Hall, S. (1997) Representation: Cultural Representations and Signifying Practices, London: Sage

Radway, J.A. (1991) Reading the Romance, Chapel Hill NC: University of North Carolina Press 